\title{
Methylprednisolone for Acute Spinal Cord Injury: 5-Year Practice Reversal
}

\author{
R. John Hurlbert, Mark G. Hamilton
}

\begin{abstract}
Objective: To re-evaluate practice patterns for methylprednisolone (MP) administration in patients with acute spinal cord injury (SCI) within the spinal surgery community across Canada five years after the publication of practice recommendations. Methods: Canadian orthopedic and neurological spine surgeons were surveyed at their respective annual meetings about their practice of steroid administration for acute SCI by means of a questionnaire comprised of the same seven questions posed five years ago plus an additional question related to change of view. Results: Forty-two surgeons and twenty-one residents directly involved in the acute management of SCI completed the questionnaire. Seventy-six percent of spinal surgeons do not prescribe MP for SCI in sharp contrast to 76\% who prescribed it five years ago. Of the $24 \%$ who use steroids, the NASCIS II dosing regimen is most commonly followed. One third of physicians continue to administer MP because of fear of litigation. Conclusions: Over a five year period there has been a complete reversal in practice patterns of MP administration for SCI, along with an increased familiarity of the published literature. Attendance at meetings, participation in local group discussions, and peer-reviewed publications appear effective in altering practice preferences arising from peer pressure and even fear of litigation.
\end{abstract}

RÉSUMÉ: La méthylprednisolone dans le traumatisme aigu de la moelle épinière : changement des habitudes de prescription depuis 5 ans. Objectif : L'objectif était de réévaluer les habitudes de pratique des chirurgiens canadiens depuis la publication des recommandations de bonne pratique concernant l'administration de la methylprednisolone (MP) chez les patients qui ont subi une lésion traumatique de la moelle épinière (LTMÉ). Méthodes : Il s'agit d'une enquête effectuée auprès des orthopédistes et des neurochirurgiens lors de leur congrès annuel respectif sur leurs habitudes de prescription de stéroïdes chez les patients qui ont subi une LTMÉ. Le questionnaire comportait sept questions identiques à celles posées il y a cinq ans et une question additionnelle sur le changement d'opinion. Résultats : Quarante-deux chirurgiens et vingt et un résidants directement impliqués dans le traitement de la LTMÉ en phase aiguë ont complété le questionnaire. Soixante-seize pour cent des chirurgiens ne prescrivent pas de MP pour une LTMÉ, contrairement à ce que faisaient $76 \%$ d'entre eux il y a cinq ans. Les $24 \%$ qui prescrivent des stéroïdes se conforment généralement au mode d'administration de NASCIS II. Un tiers des médecins continue à administrer la MP par crainte d'une poursuite judiciaire. Conclusions : Au cours des cinq dernières années, il y a eu un renversement complet des habitudes de pratique en ce qui concerne l'administration de la MP chez les patients qui ont subi une LTMÉ, de même qu'une plus grande familiarisation avec la littérature à ce sujet. La participation à des congrès et à des groupes locaux de discussion et les publications révisées par des pairs semblent efficaces pour modifier les préférences de pratique basées sur la pression des pairs et même sur la crainte de poursuites judiciaires.

Can. J. Neurol. Sci. 2008; 35: 41-45

Steroid administration in the setting of acute spinal cord injury (SCI) became popularized through the 1990's largely as a consequence of the National Acute Spinal Cord Injury Studies (NASCIS) II and III studies, each published in two segments of 6 and 12 month follow-up respectively. ${ }^{1-4}$ However, as health care institutions created and revised protocols for methylprednisolone administration, controversy arose when a number of authors published independent interpretations of the available NASCIS II and III data disputing the conclusions of the NASCIS authors. ${ }^{5-9}$ Most criticism questioned claimed statistical significance from arbitrary post-hoc analyses in the absence of clear clinical relevance. Issues were also raised with respect to appropriate statistical testing and incidence of harmful side effects.

It was amongst this controversy that the results of the first Canadian survey on steroid administration were obtained and

From the University of Calgary Spine Program and Division of Neurosurgery, University of Calgary, Calgary, Alberta.

Received April 5, 2007. Final Revisions Submitted OCtOber 11, 2007. Reprint requests to: R. J. Hurlbert, Department of Clinical Neurosciences, 12th floor, Foothills Hospital and Medical Centre, 1403 29th St. NW, Calgary, Alberta T2N 2T9, Canada. 
published. ${ }^{10}$ Disturbing to the authors was not so much the fact that the majority of Canadian spinal surgeons prescribed methylprednisolone for acute SCI, but rather that $70 \%$ of those administering it did so out of fear from being sued or from peer pressure. Only $17 \%$ of prescribing surgeons did so because they felt methylprednisolone (MP) was clinically effective.

In light of the controversy and perceived pressures to prescribe steroids for SCI, Neurosurgery, Spinal Surgery, and Emergency Medicine specialty committees conducted their own evidence-based reviews of the published literature. ${ }^{11-13}$ The conclusions were uniform; Methylprednisolone was to be regarded as a treatment option but not a standard of care. The American Association of Neurological Surgeons/Congress of Neurological Surgeons (AANS/CNS) Joint Section on Disorders of the Spine and Peripheral Nerve went so far as to say that "Treatment with methylprednisolone for either 24 or 48 hours is recommended as an option in the treatment of patients with acute spinal cord injuries that should be undertaken only with the knowledge that the evidence suggesting harmful side effects is more consistent than any suggestion of clinical benefit." To this day, the data from the National Institutes of Health (NIH) sponsored NASCIS trials have not been released for independent review, nor has MP been HPB or FDA approved for use in SCI.

Now, five years later, we re-administered the same survey to the same group of surgeons to determine if practice patterns had changed, and if so, why. The purpose of this paper is to relate the findings of this most recent survey and to contrast them with the original results, in an attempt to define change in practice preference over time.

\section{METHODS}

At the annual meetings of the Canadian Neurosurgical Association and Canadian Spine Society for the year 2006 attending neurosurgeons and orthopedic surgeons who treat acute spinal cord injured patients were asked to fill out a written one-page questionnaire consisting of the same seven questions as the original survey in 2001 (Appendix). One additional question was added examining the reasons for change in view on steroid administration: attendance at national or international meetings, discussions with colleagues, or review of published literature.

Surgeons were confronted with the questionnaire during scientific sessions throughout the venue of both meetings. They were asked to complete the questionnaire only once, and only if they were responsible for treating patients with acute spinal cord injuries. In addition neurosurgical and orthopedic residents attending these meetings were also encouraged to complete the questionnaire.

Results were tabulated and expressed as the percentage of physicians completing the form. Comparisons were drawn between the various responses to each question as well as with data from the original survey completed by 60 Canadian spinal surgeons. ${ }^{10}$ Because of the relatively small target population, subsequent sample size, and negligible statistical relevance, statistical comparisons were not made.

\section{RESUlts}

Forty-six Canadian spinal surgeons answered the one page form. Four questionnaires completed by spinal surgeons not actively participating in the care of patients with acute SCI were

\section{Detailed Understanding}

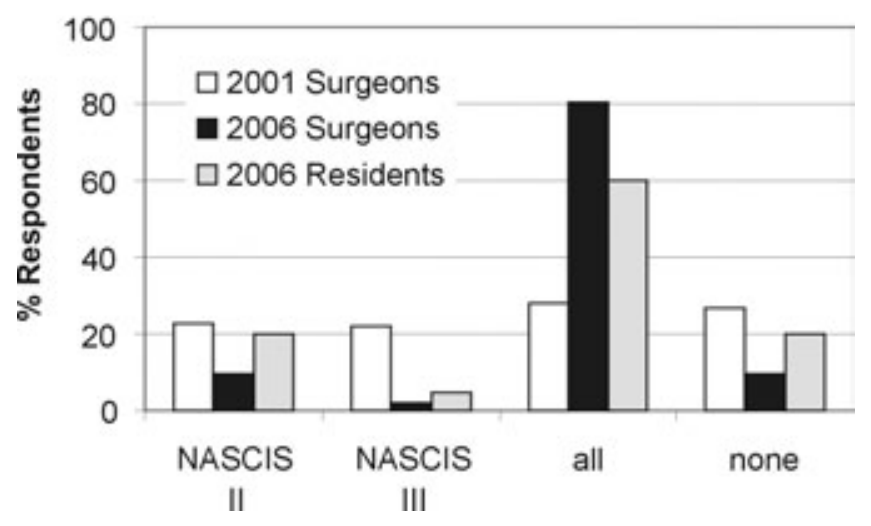

Figure 1: Familiarity with NASCIS II and III publications reported by 42 spinal surgeons who treat acute spinal cord injury. Comfort with this body of literature has increased substantially compared to the previous survey. As might be expected resident trainees as a whole are more tentative about their knowledge in this area.

excluded from analyses leaving results from 19 Neurosurgeons (45\%) and 23 Orthopedic surgeons (55\%). Twenty-one residents completed the questionnaire; all indicated ongoing responsibility for the care of these patients.

Similar to the findings of the previous survey $(n=60), 45 \%$ of surgeons indicated treating $<10$ patients with acute SCI annually while 54\% indicated treating between 10-40 (48\% and $41 \%$ respectively in 2001). Only one neurosurgeon specified treating more than 40 patients per year. Thirty three percent of residents felt they treated $<10$ spinal cord injured patients each year while $62 \%$ treated 10-40. One resident also indicated treating more than 40 acute SCI patients annually.

When asked about their knowledge of the literature $80 \%$ of spine surgeons felt they were sufficiently familiar with both NASCIS II and III trials to make their own decision about whether or not to treat with steroids, substantially improved from the previous survey (Figure 1). As might be expected within any training program, at the time of the survey residents felt less comfortable in understanding the NASCIS trials compared to qualified surgeons.

In sharp contrast to findings in 2001, the large majority of surveyed spinal surgeons no longer administer MP for acute SCI. Responses indicated $76 \%$ of treating physicians do not prescribe steroids whereas in $200176 \%$ did, representing a complete reversal of practice patterns over a five year period. Currently only $24 \%$ of Canadian Spinal Surgeons prescribe steroids for acute SCI. In general resident MP protocol preferences mirrored those of the spinal surgeons (Figure 2).

Within this minority of physicians who still use steroids, the number of orthopedic surgeons compared to neurosurgeons was roughly proportional (ortho $n=6$, neuro $n=4$ ). Interestingly, there currently appears to be a slight preference for NASCIS II 24hour dosing (60\%). Only two surgeons completing the survey continue to follow NASCIS III recommendations, while another 
Administration of Steroid Protocol

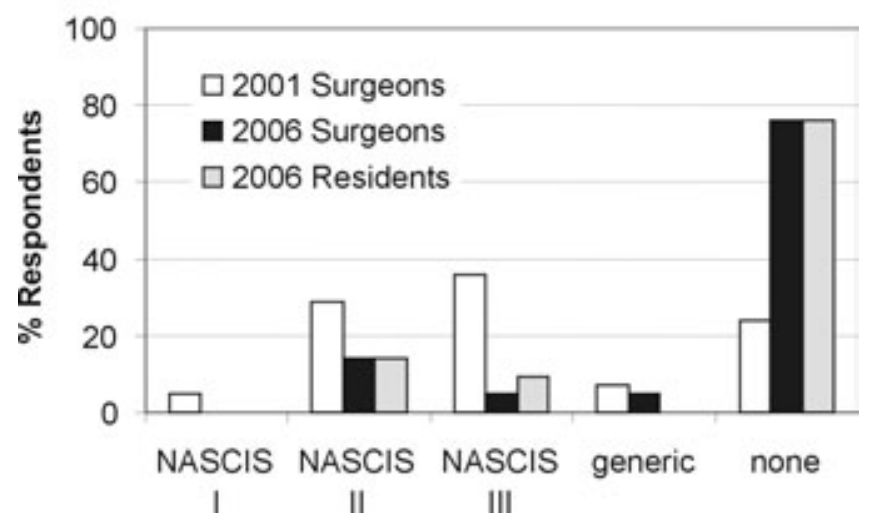

Figure 2: Prevalence of methylprednisolone administration for acute SCI amongst surveyed Canadian spinal surgeons. Nearly $80 \%$ do not administer steroids for SCI, a complete reversal of practice patterns from five years ago. NASCIS II dosing now appears more common than NASCIS III dosing, also in contrast from previous results.

two surgeons administer generic steroids (e.g. decadron) to their own protocols. These results contrast to those from five years ago where the majority of surgeons prescribing steroids favored NASCIS III doses (47\%) over NASCIS II (38\%).

Spinal surgeons prescribing MP for acute SCI were also asked about the reasons for their practice. In contrast to the previous results, peer pressure was no longer identified as a reason for administration. Most now give steroids because they feel it to be beneficial for their patients (Figure 3). However of the 24\% of Canadian Spinal Surgeons who currently administer MP for SCI,

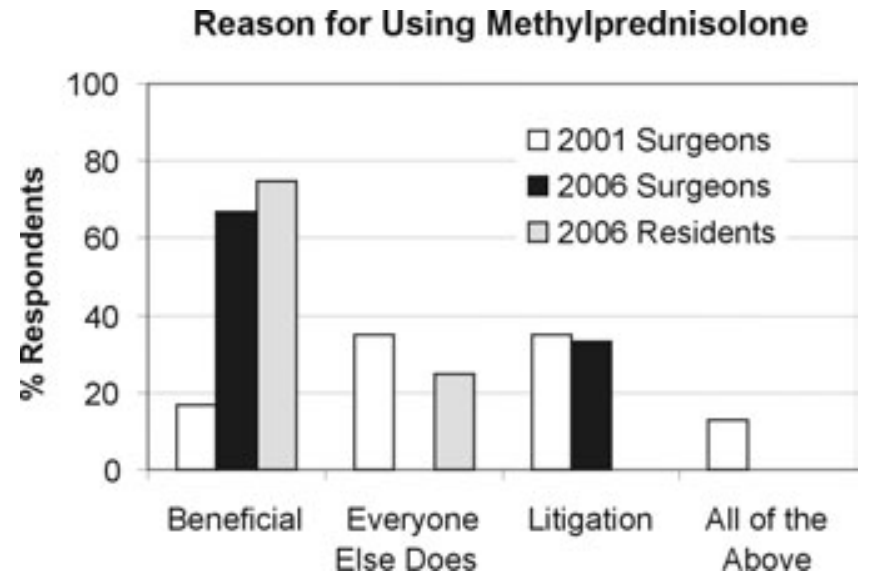

Figure 3: Reasons for prescribing methylprednisolone in SCI. Of the physicians who continue to administer this drug, most believe it has some type of beneficial effect. Although 35\% of users still do so out of fear of litigation, the actual number of surgeons practicing this type of defensive medicine is nearly 10 times less than in 2001 (see text).
$1 / 3$ do so out of fear of litigation.

When asked about the status of MP as a treatment for SCI most surgeons felt it should be considered a treatment option while a smaller groups felt it should be considered "not recommended" or "experimental". Only three surgeons believed MP should be considered a recommended treatment for acute SCI (Figure 4). Eighty-five percent of respondents admitted that their views on steroid administration had changed in the last five years. This was attributed to discussions with colleagues (9\%), reading journal articles (11\%), attending meetings $(14 \%)$, or a combination of the above (66\%).

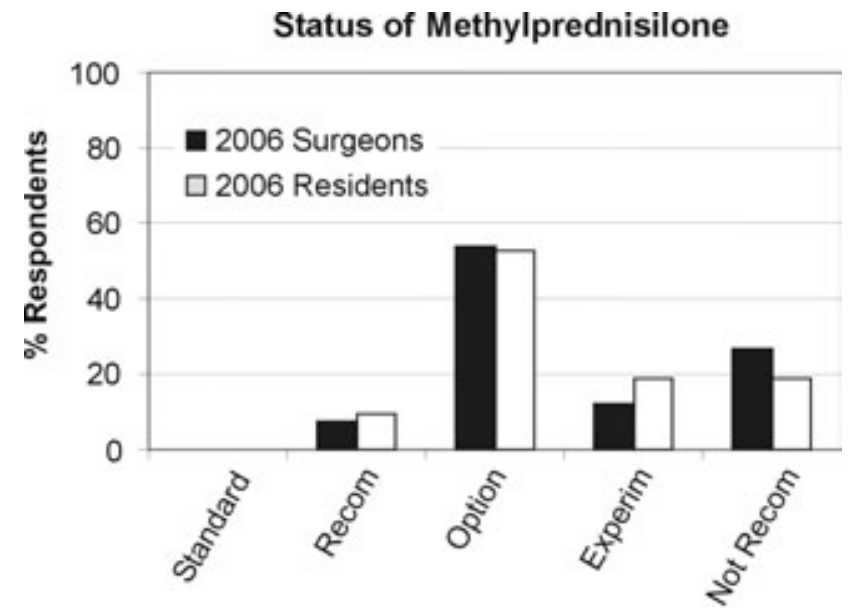

Figure 4: Perceived status of MP administration for SCI. A small majority of spinal surgeons in Canada regard the use of methylprednisolone in SCI as optional (52\%), while 38\% feel it should not be recommended at all or considered experimental. Only 3 of 42 surgeons feel it should be a therapy used in most cases of SCI (recommended treatment).

\section{Discussion}

Acute spinal cord injury is a relatively rare condition compared to other varieties of pathology encountered by the spinal surgeon. Indeed, based on the current results as well as those from five years ago, about half of the surveyed spinal surgeons treat somewhere between 10-40 patients with acute SCI per year and the other half treat less than ten. It is therefore unusual in Canada for a particular orthopedic surgeon or neurosurgeon to manage more than one-two cases of acute SCI per month. However, the severity and tragedy of the attendant neurological deficits argue loudly for consistency in "best practice" management making the results of surveys like this very important.

Although the total number of returned responses was lower than our previous survey (42 vs. 60 ), the present data originates from spinal surgeons across the country spanning Saint John's to 
Vancouver Island, and represents approximately half of the estimated number of surgeons treating acute spinal cord injury in Canada five years ago. ${ }^{10}$ With a slowly growing number of fellowship trained complex spinal surgeons and a move towards dedicated spine call rosters, it is likely that the total number of surgeons treating acute SCI has not changed since this time and may have actually decreased. Hence we feel the primary results of this survey are both representative and generalizable.

The shift in practice patterns away from steroid use over the past five years is dramatic. Not unexpectedly this change in attitude is perpetuated in resident trainees as well. The reason for this shift was identified by the respondents as stemming from information disseminated through journal publications, subspecialty meetings, and through discussions with colleagues. It is interesting to note that over the five year interval between surveys, there has been very little new evidence published with respect to the efficacy of methylprednisolone in spinal cord injury.

In 2003 Pollard et $\mathrm{al}^{14}$ retrospectively studied a group of 412 patients accumulated over an 18-year period with incomplete acute SCI and found no evidence to support high dose MP administration. Two years later, in a prospective cohort study of eight patients Qian et $\mathrm{al}^{15}$ linked myopathy to steroids administration. The same year Aito et $\mathrm{al}^{16}$ retrospectively analyzed 61 patients over 24 years with a combination of complete and incomplete injuries sustained from diving accidents. In a sub-analysis they found 30 patients presenting with acute SCI to their institution over an 8 year period, 20 of who received high-dose steroids and 10 who did not. Although the degree of improvement (motor vs. sensory, segmental vs. long-tract) is not reported, by applying logistic regression to multivariate analysis they reached statistical significance and concluded that "treatment with high dose methylprednisolone during the first $8 \mathrm{~h}$ after trauma seemed to influence the neurological outcome positively."

Indeed most of the new publications related to MP use since 2001 have been comprehensive reviews of previously published evidence attempting to dissect truth from fiction. ${ }^{11-13,17,18}$ It is these latter publications, including position statements from three subspecialty organizations that are likely to have facilitated the sharp decrease in steroid administration observed in this study. These publications and the meeting presentations arising from them are also likely responsible for the fact that in 2001 only $30 \%$ of spine surgeons felt they understood the steroid literature while five years later $80 \%$ do.

Similarly, results from the original survey showed that $53 \%$ of the entire survey population prescribed MP out of fear of litigation or from peer pressure. Clearly in an age of evidence based medicine and "best practice" these were not, nor are they today desirable motivators for practice patterns. Currently in Canada the number of surgeons prescribing MP for the "wrong" reasons has dropped by an order of magnitude to $7 \%$. Implicit in this observation is that peer-reviewed independent interpretation of published results and organization-sponsored guideline publications are powerful tools guiding practice preferences. This gives reason to hope that "defensive medicine" (i.e. medical practice arising from fear of being sued) is not totally at the whim of our well intentioned but occasionally misguided courts.

While some investigators continue to examine clinical indications for methylprednisolone administration in SCI,${ }^{19}$ there are no currently operational prospective protocols designed to further investigate efficacy of MP. In sharp contrast to the Cochrane publications authored by the NASCIS principle investigator, ${ }^{20-22}$ the most recent independent evidence-based reviews still come to the same conclusion: "There is insufficient evidence to support the use of methylprednisolone as a standard treatment in acute spinal cord injury". ${ }^{18}$ The responses generated from the present survey suggest that, at least in Canada, the message is finally getting through.

\section{Conclusions}

Over a five year period since 2001, attitudes and practice patterns with respect to MP administration in acute SCI have completely reversed. The large majority of spinal surgeons (76\%) no longer prescribe MP in this setting. Eighty percent of surgeons now feel comfortable with the pertinent published literature compared to $30 \%$ previously. Of the $24 \%$ of orthopedic surgeons and neurosurgeons who continue to recommend MP for SCI, the majority do so because they believe it efficacious, not because of fear of litigation. Peer-reviewed independent interpretation of published results, guidelines formulation by parent organizations, and dissemination at specialty meetings are powerful tools for influencing practice patterns.

\section{REFERENCES}

1. Bracken MB, Shepard MJ, Collins WF, Holford, TR, Young W, Baskin D, et al. A randomized, controlled trial of methylprednisolone or naloxone in the treatment of acute spinal-cord injury: results of the second national acute spinal cord injury study. N Engl J Med. 1990;322:1405-11.

2. Bracken MB, Shepard MJ, Collins WF, Holford TR, Baskin D, Eisenberg HM, et al. Methylprednisolone or naloxone treatment after acute spinal cord injury: 1-year follow-up data. J Neurosurg. 1992; 76:23-31.

3. Bracken MB, Shepard MJ, Holford TR, Seo-Summers L, Aldrich $\mathrm{EF}$, Fazl M, et al. Administration of methylprednisolone for 24 or 48 hours or tirilazad mesylate for 48 hours in the treatment of acute spinal cord injury. JAMA. 1997;277:1597-1604.

4. Bracken MB, Shepard MJ, Holford TR, Leo-Summers L, Aldrich EF, Fazl M, et al. Methylprednisolone or tirilazad mesylate administration after acute spinal cord injury: 1-year follow-up. J Neurosurg. 1998; 89:699-706.

5. Nesathurai S. Steroids and spinal cord injury: revisiting the NASCIS 2 and NASCIS 3 trials. J Trauma. 1998;45:1088-93.

6. Coleman WP, Benzel E, Cahill DW, Ducker T, Geisler F, Green B, et al. A critical appraisal of the reporting of the National Acute Spinal Cord Injury Studies (II and III) of methylprednisolone in acute spinal cord injury. J Spinal Disord. 2000; 13(3):185-99.

7. Hurlbert RJ. Methylprednisolone for acute spinal cord injury: an inappropriate standard of care. J Neurosurg. 2000;93:1-7.

8. Short DJ, El Masry WS, Jones PW. High dose methylprednisolone in the management of acute spinal cord injury: a systematic review from a clinical perspective. Spinal Cord. 2000;38: 273-86.

9. Hurlbert RJ. The role of steroids in acute spinal cord injury: an evidence-based analysis. Spine. 2001;26(24S):S39-46.

10. Hurlbert RJ, Moulton R. Why do you prescribe methylprednisolone for acute spinal cord injury? Can J Neurol Sci. 2002;29:236-9.

11. Hugenholtz H, Cass DE, Dvorak MF, Fewer DH, Fox RJ, Izukawa DM, et al. High-dose methylprednisolone for acute closed spinal cord injury: only a treatment option. Can J Neurol Sci. 2002;29:227-35.

12. Hadley MN, Walters BC, Grabb PA, Oyesiku NM, Przybylski GJ, Resnick DK, et al. Pharmacological therapy after acute spinal cord injury. Neurosurgery. 2002;50Suppl:63-72.

13. Bledsoe BE, Wesley AK, Salomone P. High-dose steroids for acute 
spinal cord injury in emergency medical services. Prehosp Emerg Care. 2004;8(3):313-16.

14. Pollard DE, Apple DF. Factors associated with improved neurological outcomes in patients with incomplete tetraplegia [clinical case series]. Spine. 2003;28(1):33-8.

15. Qian T, Guo X, Levi AD, Vanni S, Shebert RT, Sipski ML. Highdose methylprednisolone may cause myopathy in acute spinal cord injury patients. Spinal Cord. 2005;43:199-203.

16. Aito S, D'Andrea M, Werhagen L. Spinal cord injuries due to diving accidents. Spinal Cord. 2005; 43(2):109-16.

17. Hurlbert RJ. Strategies of medical intervention in the management of acute spinal cord injury. Spine. 2006;31(11):516-21.

18. Sayer FT, Kronvall E, Nilsson OG. Methylprednisolone treatment in acute spinal cord injury: the myth challenged through a structured review of the literature. Spine. 2006;6: 335-43.

19. Leypold BG, Flanders AE, Schwartz ED, Burns AS. The impact of methylprednisolone on lesion severity following spinal cord injury. Spine. 2007;32(3):373-78.

20. Bracken MB. Pharmacological interventions for acute spinal cord injury. Cochrane Database of Systematic Reviews (2): CD001046, 2000.

21. Bracken MB. Steroids for acute spinal cord injury (update). Cochrane Database of Systematic Reviews (3):CD001046, 2002.

22. Bracken MB. Steroids for acute spinal cord injury (update). Cochrane Database of Systematic Reviews (2):CD001046, 2007.

\section{APPENDIX \\ Steroid Survey Questionnaire}

1. I am $a$

(check one only)
a) Neurosurgeon
b) Orthopedic Surgeon
c) Research Scientist
d) Resident / fellow in training
e) None of the above

2. I manage spinal cord injured patients

(check one only)
a) Yes
b) No

3. I treat_?_acute Spinal Cord Injuries (SCIs) a year (check one only)
a) $<10$
b) $10-40$
c) $>40$

4. I administer steroids to patients with acute SCI based on (check one only)

a) NASCIS I guidelines

b) NASCIS II guidelines

c) NASCIS III guidelines

d) A Generic steroid protocol

e) I do not give my acute SCI patients steroids (skip to question 6)

\section{I administer steroids because} (check one only)
a) I believe they produce significant improvement in patients with SCI
b) I am worried about being sued
c) Everyone else does
d) All of the above

6. I have read in detail and understand the results of (check one only)
a) The NASCIS II study
b) The NASCIS III study
c) All of the above
d) None of the above

7. For Non-Penetrating SCI, Methylprednisolone should be considered

(check one only)

a) A Standard of Care (eg. insulin for diabetes)

b) A Recommended Treatment (eg. beta blocker for hypertension)

c) A Treatment Option (eg. amoxicillin or septra for Group A strep)

d) An Experimental Therapy

e) Not Recommended

8. In the last 5 years my views on Methylprednisolone for SCI have:

(check all that apply)

a) Changed because of journal articles I have read

b) Changed because of meetings I have attended

c) Changed because of discussions with my colleagues

d) Not changed at all 